\title{
Some numerical approaches of creep, thermal shock, damage and delayed failure of ceramics and refractories
}

\author{
MICHEL BOUSSUGE \\ Ecole des Mines de Paris - Centre des Matériaux P.M. Fourt, B.P. 87, 91003 EVRY Cedex, France
}

\begin{abstract}
Numerical simulation is now very often used to predict the behaviour of components in service conditions. This paper is interested in specific approaches concerning ceramic materials and refractories. Creep can be satisfactorily described by a kinematic hardening, and exhibits different creep rates in tension and compression. Concerning the thermal shock of materials, the numerical approach depends whether or not the material is able to develop a sprayed out damage, leading to micro- or macro-cracking. Finally, delayed failure at high temperature can be considered as a consequence of creep, but the random aspect of failure seriously complicates the numerical models. The lack of experimental data presently limits the calibration and the validation of the numerical models.
\end{abstract}

Keywords. Ceramic; refractories; creep; thermal stock; damage; delayed failure; numerical simulation.

\section{Introduction}

Numerical simulation is now extensively used in industry to design components and to calculate the various loadings associated to the use of the system in which the part is integrated. In particular, for mechanical purposes, the mesh generated during the design of the component is often used to calculate, with finite element method, the stresses and strains generated by the working conditions. In parallel, the recent and rapid increase of the amount of materials available on the market did not leave enough time to collect data on the mechanical and thermal properties of new materials. Then the problem for the designer is generally not to get powerful computers and finite element programs, but to have reliable behaviour constitutive equations able to predict damage of the component in service conditions. This is particularly true for materials used at high temperature such as intermetallic compounds or ceramics.

The case of ceramics is particularly critical for different reasons. Firstly, because these materials have not yet many industrial applications which may lead to the study of their high temperature mechanical properties. Secondly, because ceramic materials exhibit particular mechanical features (for example, brittleness, low fracture strains, ...), which seriously complicate the experimental characterization of the material behaviour, especially at the very high temperatures which can be reached by ceramics. Finally, modelling the ceramic mechanical behaviour also needs specific tools to allow finite element calculation.

This paper intends to rapidly describe some recent developments carried out in that field at our laboratory concerning creep, thermal shock, damage and delayed failure of ceramics and refractories.

\section{Discussions}

\subsection{Creep}

Most of the studies concerning the creep of ceramic materials reported in the literature have been interested in steady-state creep described by a Norton type law. The authors essentially examined the relationship between the parameters of this law (stress exponent and activation energy) and the deformation mechanisms acting within the materials (Cannon and Langdon 1983, 1988). From the point of view of mechanics, the study of the creep of refractory materials has been limited by the difficulty of gripping specimens and measuring low strains at high temperature. For this reason, most of the researchers performed compressive or bending tests and, most rarely, tensile tests.

Owing to a specific tensile testing device developed at our laboratory (Ienny and Boussuge 1991; Ienny 1992), a comparison has been done between the response of different materials submitted to tensile or compressive stresses. As shown in figure 1 for sintered silicon nitride, it has been proved that the creep rate is generally higher in tension (Croizet 1992).

As the creep law used for predicting the behaviour of actual components must be able to describe accurately the response to various types of loading, a right choice of the law must be done. Partial unloading sequences during creep (dip-tests) allowed the observation of a reverse creep (figure 2), showing that the type of hardening acting in ceramic materials and in refractories is kinematic rather than isotropic. The main constitutive equation of creep in uniaxial stress state can then be explained as (Chaboche 1989; Croizet 1992; Croizet et al 1992; Ienny et al 1993): 


$$
\frac{\mathrm{d} \varepsilon}{\mathrm{d} t}=\operatorname{sgn}(\sigma-X)\left|\frac{(1-\alpha)|\sigma-X|+\alpha(\sigma-X)-R}{K}\right|^{n}
$$

in which $X$ is an internal stress which develops in the material (function of the applied stress), $K$ and $n$, two parameters of the creep law, $\alpha$ a parameter characterizing the asymmetry of the creep ( $\alpha=0$ for a symmetric behaviour and $\alpha=0.5$ for a pure elastic behaviour in compression), and $R$ the hardening stress.

After the numerical identification of the values of the parameters from a sufficient experimental database, such a law can be introduced in a finite element calculation code, in order to predict the deformation of actual structures.

\subsection{Thermal shock}

A feature of thermal loadings is that they induce imposed strains within the material. The response of the material to such loadings directly depends on its mode of damage.

For materials in which the only way of stress accommodation is macrocracking (this is generally the case for dense, strong ceramics), one or several cracks suddenly propagate in the material, as soon as the strength of the material is reached. However, in the case of brittle materials, this simple criterion is complicated by the random aspect of brittle failure. From the thermoelastic stress fields calculated using a finite element code, a post-

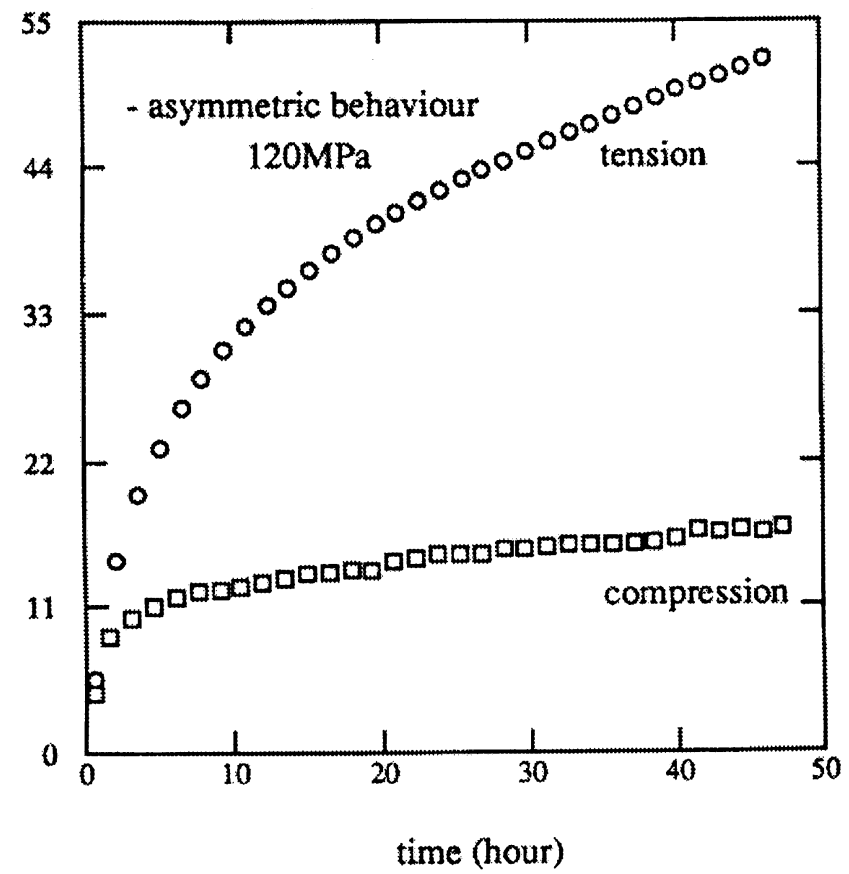

Figure 1. Comparison of the creep rates in tension and compression for SSN. processor has to be used in order to calculate the associated failure probability. A Weibull type law is generally introduced in a post-processor to identify the most critical zones of a component (locations in which the failure probability is maximum), and the failure probability of the whole component when submitted to various thermal loadings.

The case of the materials able to develop a sprayed out damage (for example most of the refractories having a coarse microstructure) is quite different. Damage is then able to lead to a stress relaxation through microcracking of the material. For numerical simulation, the damage is generally taken into account by a decrease in the Young's modulus of the material, with a Kachanov-Rabotnov (Kachanov 1986; Fritz-Chateau 1999) type equation:

$$
E_{\mathrm{d}}=E_{0}(1-D)
$$

in which $E_{0}$ is the elastic modulus of the undamaged material, $E_{\mathrm{d}}$ the modulus of the damaged material and $D$ the damage parameter varying between 0 and 1 . The main problem is then to identify a law allowing $D$ to be calculated, versus the stress and/or strain history of the material. This is not a simple question because imposed strain experiments are not easy to carry out, as well as reliable measurements of elastic moduli of damaged material. Microcracks are also difficult to reveal and to count, especially in porous materials.

\section{total strain (x 10e-4)}

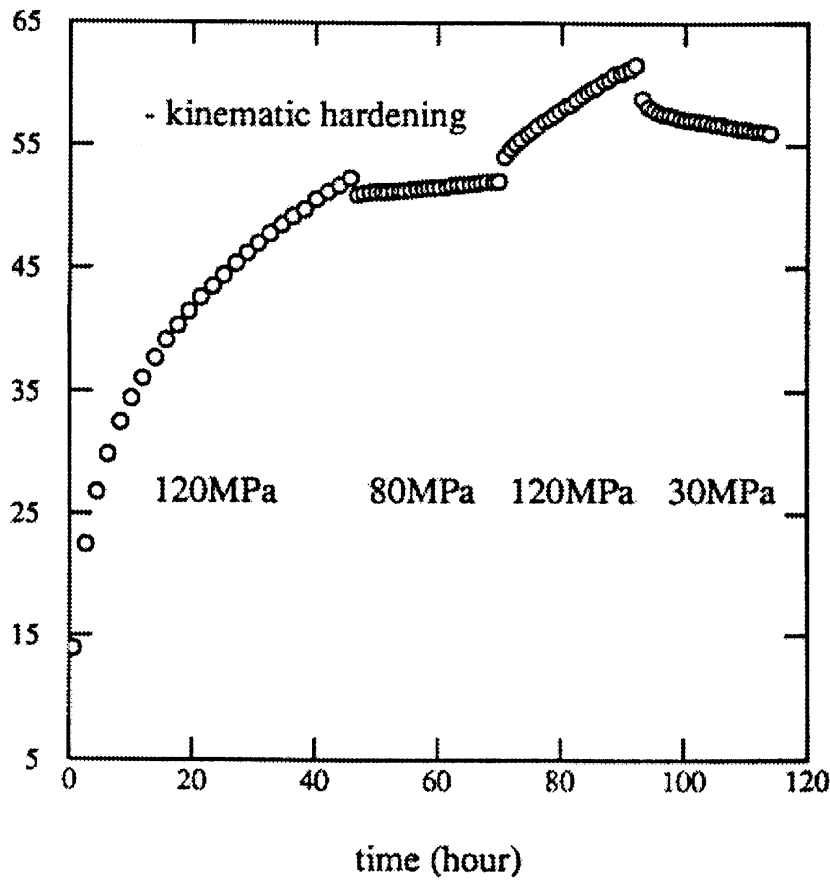

Figure 2. Dip-test on SSN: reverse creep during unloading at $30 \mathrm{MPa}$. 


\subsection{Delayed failure}

Delayed failure of ceramic materials is probably one of the most complex phenomena to simulate with finite element method. Moreover, experimentally, numerous experiments are necessary to calibrate and to validate the developed models. As delayed failure is generally caused by slow crack growth from flaws pre-existing within the material, because of corrosion or creep (Boussuge 1991, 1993), the times to failure are randomly distributed. In order to avoid the simulation of crack growth which is complex and takes time, one generally prefers continuous medium approaches, more or less based on physical bases.

From a physical base, the simulation of delayed failure first requires a good description of the initial flaws distribution. This has been obtained using an initial, random distribution of damage in the finite elements constituting
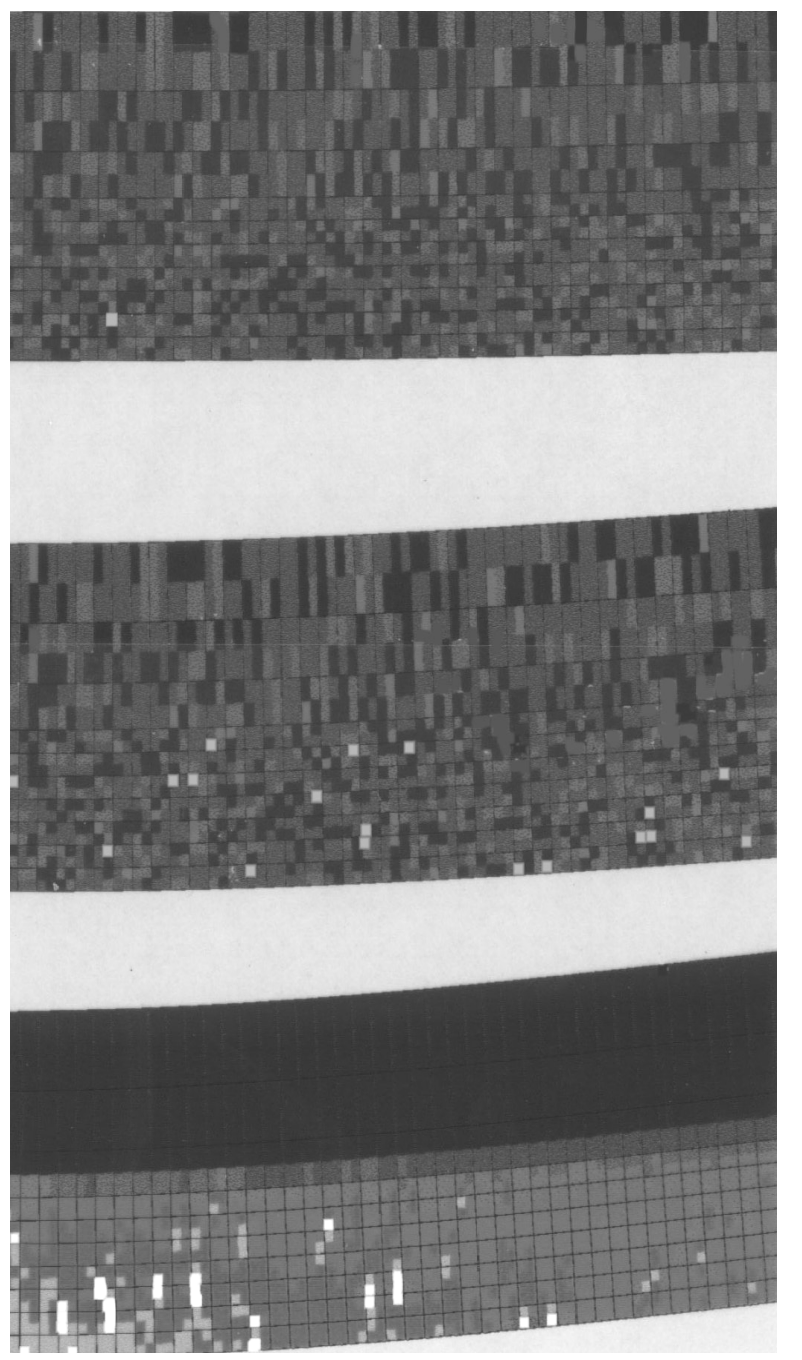

Figure 3. Deflection and damage extension during creep of RBSC. the mesh. In a finite element $i$ containing an initial value of damage $D_{i}$, an effective stress $\sigma_{\text {effi }}$ is defined from the calculated stress $\sigma_{i}$ by (Gutmann-Ambroise 1997; Gutmann et al 1997):

$$
\sigma_{\mathrm{effi}}=\frac{\sigma_{i}}{1-D_{i}} .
$$

Failure occurs when this value reaches the strength of the material, the initial distribution being set to describe the brittle random failure in the virgin material. Then, a function has to be defined, describing the increase in damage associated to creep or corrosion versus time and loading history of the material. For each initial random damage distribution, the calculation leads to time and location of failure, which can be compared with experiments. Figure 3 shows, from top to bottom, an example of damage extension (clear areas) in a half central part of a reaction bonded silicon carbide specimen submitted to 3-point bending (the centre is on the left and the tensile side on the bottom). Using this method, many calculations from different initial states, high time consuming, are necessary to obtain a distribution of locations and times to failure.

For this reason, another method based on the use of a post-processor describing the brittle random failure (Weibull statistics) has been developed (GutmannAmbroise 1997). In that method, creep or corrosion affecting the material modify the Weibull parameters, leading to a calculation of a failure probability based on different parameters at each step of ageing time. A single calculation is then necessary to obtain the increasing probability of failure versus time. An example of comparison between experiments and calculation is given in figure 4 for delayed failure of reaction bonded silicon carbide during 3-point bending tests.

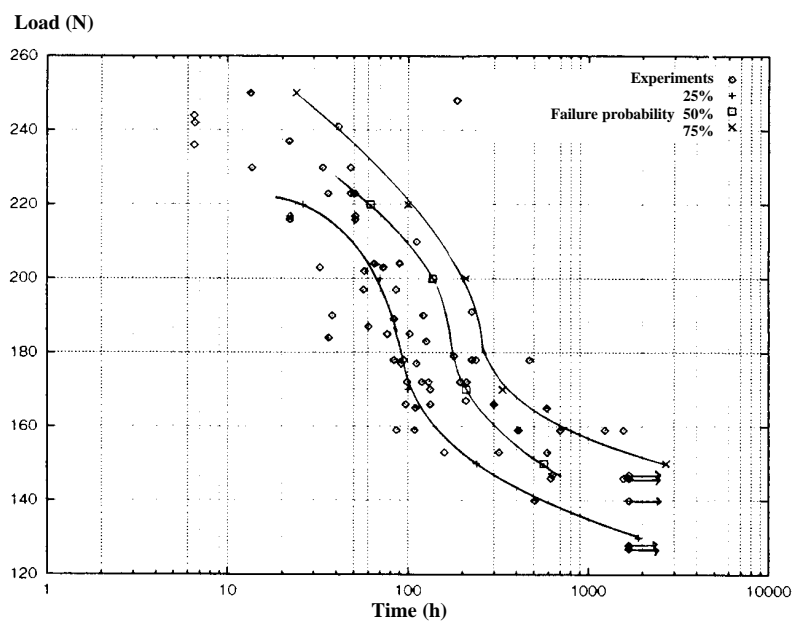

Figure 4. Comparison between measured and calculated lifetimes versus load for RBSC. 


\section{Conclusions}

Specific computational methods have been developed for simulating the mechanical behaviour of ceramics and refractories. Modern computers and finite element codes allow user-friendly procedures to be used for particular applications. However, strong experimental databases are absolutely necessary to calibrate and validate the numerical models, especially for materials having a random fracture. For ceramics and refractories, the main problem remains the insufficiency of experimental data concerning high temperature mechanical properties of materials.

\section{Acknowledgements}

This paper has been written from several Ph.D. Theses carried out at 'Ecole des Mines'. Patrick Ienny, Didier Croizet, Martine Gutmann-Ambroise and Marielle FritzChateau are gratefully acknowledged.

\section{References}

Boussuge M 1991 Eng. Frac. Mech. 40855

Boussuge M 1993 3rd Japan international S.A.M.P.E symposium (eds) T Kishi, N Takeda and Y Kagawa (Tokyo: Japan Chapter of SAMPE ) p. 2032

Cannon W R and Langdon T G 1983 J. Mater. Sci. 181

Cannon W R and Langdon T G 1988 J. Mater. Sci. 231
Chaboche J L 1989 Int. J. Plast. 5247

Croizet D 1992 Experimental and numerical study of the high temperature mechanical behaviour of silicon nitride, Ph.D. Thesis, Ecole des Mines de Paris, France

Croizet D, Méric L, Boussuge M and Cailletaud G 1992 1st European conference on numerical methods in engineering (eds) C Hirsch, O C Zienkiewicz and E Onate (Amsterdam: Elsevier) p. 741

Fritz-Chateau M 1999 Thermomechanical study of refractories for core-catcher application, Ph.D. Thesis, Ecole des Mines de Paris, France

Gutmann-Ambroise M 1997 Experimental and numerical study of high temperature behaviour and fracture of technical ceramics, Ph.D. Thesis, Ecole des Mines de Paris, France

Gutmann M, Cailletaud G and Boussuge M 1997 5th European ceramic society conference and exhibition ECerS (eds) D Bortzmeyer et al (Versailles, France: Trans Tech Publications) Vol. 1, pp. 702-705

Ienny P 1992 Creep of reaction-bonded ceramics: relationship with microstructure, Ph.D. Thesis, Ecole des Mines de Paris, France

Ienny P and Boussuge M 1991 2nd European ceramic society conference: Euro-ceramics II (eds) $\mathrm{G}$ Ziegler and $\mathrm{H}$ Hausner (Köln: ed Deutsche Keramische Gesselschaft e.V.) 2, p. 1221

Ienny P, Gutmann M and Boussuge M 1993 3rd European ceramic society conference: Euro-ceramics (eds) P Duran and J F Fernandez (Madrid, Spain: Faenza Editrice Iberica S.L., Castellón de la Plana) 3, p. 357

Kachanov L M 1986 Introduction to continuum damage mechanics (Dordrecht: Martinus Nijhoff Publishers) 